\title{
LAS MUJERES EN LA PRENSA DE CARTAGENA DE Indias, 1900-1930. Autora Gloria BONILLA VÉLEZ
}

\section{Carolina Marrugo Orozco ${ }^{1}$}

Liset Martínez Rincón ${ }^{2}$

Las primeras décadas del siglo XX, marcaron una nueva etapa dentro de la historiografía en Colombia. La incursión de las mujeres en la historia-como sujeto de estudioy del género, como método de análisis, se constituyó en un gran aporte teórico, metodológico y epistemológico que trascendió en América Latina y el mundo.Sobre todo, "[...] el auge de la segunda ola del feminismo de los años 70 , contribuyó notablemente al posicionamiento y legitimación de la historia de las mujeres [... $]^{\prime 3}$

${ }^{1}$ Estudiante $\mathrm{V}$ semestre del Programa de Historia. Miembro del semillero de
investigación Estudios de Familias, Masculinidades y Feminidadesde la Facultad de Ciencias Sociales y Educación de la Universidad de Cartagena.

2 Estudiante VI semestre del Programa de Historia. Miembro del semillero de investigación Estudios de Familias, Masculinidades y Feminidades de la Facultad de Ciencias Sociales y Educación de la Universidad de Cartagena.

${ }^{3}$ Gloria Bonilla Vélez, Las mujeres en la prensa de Cartagena de Indias, 1900-1930 Cartagena, Ed. Universidad de Cartagena, 2011, pp. 22.

${ }^{4}$ Ver: SCOTT, J: “El género una categoría útil para el análisis histórico". En J. Amelang y M. Nash (Editores): Historia y Género. Las mujeres en la Europa moderna y contemporánea, Valencia.Alfons El Magnanim, 1990.

${ }^{5}$ Op .cit. Bonilla, P.P. 1
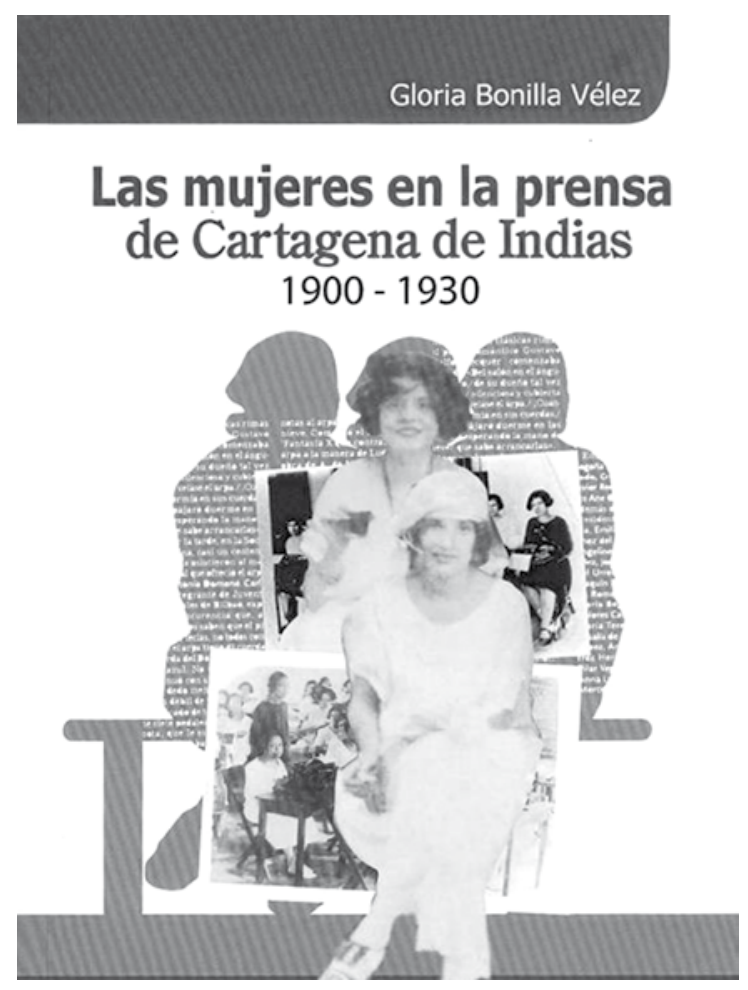

A mediados de los años noventas, en Colombia, la academia ya ostentaba una considerable producción historiográfica para este tema, en este sentido, la influencia de grandes teóricos como Joan Scott ${ }^{4}$ fueron determinantes. Como resultado de la diversificación de los estudios de la mujer, la historiadora Gloria Bonilla Vélez, nos muestra en su libro Las mujeres en la prensa de Cartagena de Indias, 1900-1930, una investigación que, en sus propias palabras: "trata, [...], de las relaciones entre prensa, género, discurso y poder, y las formas cómo ellas se interpelan y se interrogan $[\ldots]^{\prime \prime 5}$

La trayectoria académica de Bonilla, inicia en la Universidad de Antioquia y la Universidad Nacional de Colombia, donde obtiene sus títulos de Historiadora y Magíster en Historia, respectivamente. Desde ese momento, su labor académica 
fructificó en numerosas publicaciones-producto de su participación en grupos de investigación-que siguen la línea del género, mujeres, familias, prensa y migraciones transnacionales. Como resultado de su trabajo de Tesis Doctoral, presentada a la Universidad de Pablo de Olavide en España, se encuentra el texto aquí reseñado, cuyo contenido se resume en cuatro capítulos.

El objetivo principal del texto es mostrar cómo eran representadas las mujeres a través de la prensa durante los primeros decenios del siglo XX, período en el cual se suscitaron grandes cambios en la sociedad colombiana que afectaron directamente a las mujeres. En este sentido, la autora plantea como tesis que la prensa fue una herramienta de opinión determinante para fijar y fomentar unos discursos sobre la mujer y lo femenino.

En consecuencia, la autora nos invita a un recorrido a través de la prensa y sus representaciones de la mujer, indistintamente de la clase social (élites, sectores populares), etnia y espacio en el que se encontraran (entre lo privado o público). Además, considera el rol de la prensa como actor político ${ }^{6}$ y legitimador de un discurso hegemónico.

El soporte documental de la investigación está basado en la prensa y periódicos obreros conservados en diferentes archivos del país, además de un amplio soporte bibliográfico. Según Bonilla, en su investigación, la prensa actúa en doble sentido: como fuente informativa e interpretativa ${ }^{7}$ permitiéndole comprender el contexto que investiga. Entre tanto, el concepto de género es concebido como una categoría que le permite denotar las relaciones sociales entre hombres y mujeres.

En el recorrido por el mundo de las representaciones a través de la prensa, el primer capítulo, nos da cuenta de la evolución histórica y de una revisión historiográfica de la historia de las mujeres, en donde se destaca el aporte de autores, en cronologías específicas de estudio. En consecuencia, la autora realiza un recorrido historiográfico desde las sociedades aborígenes, transitando por la colonia y el período de independencia, para finalizar en el siglo XX, período en el cual se detiene su investigación. En cada etapa, anota cómo los autores describen las sociedades que analizan, a partir de la categoría género.

Bonilla Vélez, nos muestra el origen y avance de la historia de las mujeres en Colombia, contrastándola con Europa y América Latina. El desplazamiento histórico al que nos incita la profesora, devela no solo una cronología, sino

${ }^{6}$ Ver: L. M. Glave: “Entrevista con Francois-Xavier Guerra: Considerar el periódico mismo como un actor". En: Debates y Perspectivas. 3, 2003.

${ }^{7}$ Op .cit. Bonilla, P.P.4 
perspectivas, influencias y aportes que han contribuido a fortalecer el estudio de la historia de las mujeres a nivel nacional e internacional.

Por otro lado, la autora establece la relación entre prensa, modernidad y género. El período estudiado no deja de ser revelador, pues la irrupción de la modernidad en Colombia, suscita rupturas, aunque también continuidades. Ciertos elementos que se gestaron en la sociedad decimonónica, se visibilizan aún más, como la consolidación de una opinión pública, estimulada por diversas publicaciones. De ahí que la prensa constituya un instrumento pedagógico y articulador de discursos y representaciones. Bonilla Vélez, también deja entrever que la modernización- aunque produjo cambios- no siempre implicó transformaciones en cuanto a las relaciones de género, sino reafirmaciones de los roles en ciertos aspectos de la vida cotidiana. Factores como la legislación y la intervención de la iglesia católica, limitaron espacios concedidos a la mujer, como la educación, la lucha por la ciudadanía y el espacio laboral.

En el segundo capítulo, la autora nos señala las representaciones sociales de la mujer en la prensa de Cartagena de indias en el ámbito privado. En este sentido, Bonilla Vélez, registra las concepciones que se tenían del "deber ser" que- dentro del ciclo vital, etapas de desarrollo y condición femeninas-se determinaban a nivel social y cultural para las mujeres, justificado a partir de la imposición de parámetros normativos direccionados por la iglesia católica y la ley civil, todos argumentados desde concepciones que parten de la superioridad masculina.

El tercer capítulo, muestra las representaciones sociales de la mujer en el espacio público. La investigadora inscribe un hecho relevante en la historia de las mujeres, y es su conquista en el ámbito laboral. En la relación que muestra la autora de mujer, trabajo y economía, revela la obligada incursión de la mujer al ámbito laboral -por diversas circunstancias -, los conflictos familiares y sociales que produjo esta decisión, la conquista de espacios de lucha por la dignificación del salario, la exclusión laboral y el reto de enfrentar la estigmatización desde la prensa y la opinión. De igual forma, indica la ampliación del terreno laboral para las mujeres, la importancia que cobran ciertos oficios como prolongación del ideal doméstico, la proyección de la mujer en el ámbito público y su extensión a la esfera política con acercamientos a la ideología socialista.

Finalmente, el último capítulo, nos enfrenta a los modelos de transgresión femenina, señalando las representaciones de la mujer en el mundo público de 
la prostitución y la delincuencia. A través del análisis de casos, Bonilla Vélez, nos lleva a razonar más allá de los prejuicios. Deja ver a la mujer como sujeta con numerosos conflictos, no solo sociales, sino internos. Señala que, como resultado de la confluencia de dichos problemas, su condición humana hace brotar la violencia como desahogo, mientras que la delincuencia y la prostitución se constituyen en mecanismos de supervivencia frente a los altibajos del mundo moderno: pobreza, enfermedades, desempleo, abandono, etc.

La historiadora nos muestra, en esta investigación, que, si bien las mujeres han sido partícipes activas de los procesos históricos en nuestro país, los cambios suscitados en la primera mitad del siglo XX, la confrontaron a una realidad desconocida, pues el yugo patriarcal le confirió una identidad pasiva que no era consecuente con su nueva realidad. Por ello, la transgresión hace su aparición- quizá con mayor fuerza -en una época en la que la mujer se enfrenta a múltiples cambios.

La transición de la mujer del ámbito privado a uno público, no fue fácil y estuvo marcado por instituciones reguladoras y discursos desde la prensa. Esta última, sin duda, influyó para crear ciertas imágenes representativas "positivas" o "negativas" de lo femenino. La autora revela, en cada una de los espacios de representación, el papel de la prensa como agente difusor de modelos ideales y/o estigmatizadores de lo femenino.

Así pues, Las mujeres en la prensa de Cartagena de Indias, 1900-1930, es un trabajo que analiza, desde una perspectiva micro, las representaciones quedesde las publicaciones- se hizo de la mujer y de sus espacios de sociabilidad, pero también distingue el componente humano. Este texto nos invita a comprender que las representaciones no definen ni objetos ni sujetos, sino que son construcciones históricas propias del contexto en que se fundan. En este sentido, el texto de la profesora Gloria Bonilla Vélez constituye un gran aporte para entender el sentido de los discursos y de las construcciones de las que somos objetos en nuestra sociedad.

Este trabajo ha contribuido de manera significativa a la producción historiográfica regional y nacional, en lo que se refiere al tema de la prensa y su pregunta por las mujeres. Sin embargo, se hace necesario que nuevos trabajos sobre la prensa y la mujer, permitan establecer un enfoque comparativo, con el cual se puedan confrontar los planteamientos de Bonilla y, seguramente, de futuras investigaciones. En ello reside la finalidad de la investigación histórica. 